\title{
Pulmonary ultrasound imaging in the hemodynamic evaluation in the early post-operative period of cardiac surgery
}

\section{Imagen del ultrasonido pulmonar en la evaluación hemodinámica en el postoperatorio temprano de cirugía cardíaca}

\author{
Luis E. Santos-Martínez",2*, Miguel Á. Hernández-Márquez, Jessica Garduño-López, \\ Efrén Melano-Carranza1, Gastón Mendoza-Copa1, Gustavo Rojas-Velazco', \\ Guillermo Fernández de la Reguera-Fernández del Campo', Francisco M. Baranda-Tovar', \\ and Rolando J. Álvarez-Álvarez ${ }^{1}$
}

${ }^{1}$ Department of Cardiovascular Postsurgical Intensive Care, Secretaría de Salud, Instituto Nacional de Cardiología Ignacio Chávez; ${ }^{2}$ Department of Pulmonary Hypertension and Right Heart, Instituto Mexicano del Seguro Social (IMSS), Centro Médico Nacional Siglo XXI, Mexico City, Mexico

Heart surgery post-operated (POP) patients are a population of medical-surgical care with characteristics of their own according to the type of procedure they undergo since during the surgery they are assisted with a cardiopulmonary bypass pump, they require blood transfusions and are likely to experience inherent acute cardiopulmonary complications in the trans-operative period $^{1}$. Furthermore, they need invasive and non-invasive hemodynamic surveillance, and their hemodynamic profile generally has to be determined under sedation and mechanical ventilation in the early post-operative period ${ }^{1,2}$.

Their evolution in the early POP period in a post-operative cardiovascular intensive care unit (PCICU) can be uneventful or with acute complications, such as low cardiac output syndrome ${ }^{2}$, pulmonary congestion (pulmonary edema, extravascular lung water [EVLW]), or cardiogenic shock of diverse origins requiring further intervention, such as administration of drugs with inotropic activity, counterpulsation balloon, or even extracorporeal membrane oxygenation (ECMO), which implies further impairment of their hemodynamic behavior ${ }^{1-5}$.

In the PCICU, hemodynamic profile is determined by the thermodilution method with a flotation catheter in the pulmonary artery (Swan-Ganz) and the presence of EVLW through chest X-ray and thermodilution ${ }^{5-7}$. Cardiopulmonary evaluation can be complemented with lung ultrasound (L-US), which is also a tool that can calculate the presence of EVLW and support its evolution with specific treatment ${ }^{8}$. In patients undergoing a heart surgery procedure, the number of B-lines has been associated with the amount of EVLW ${ }^{9}$.

However, the hemodynamic profiles that can occur after heart surgery can be diverse, although not all of them occur in a single patient; for this reason, L-US imaging could be different depending on the category of the hemodynamic profile obtained at admission or within the $1^{\text {st }} 12-24 \mathrm{~h}$ of PCICU stay. For this reason, an exploratory examination of the possible images that would result according to the hemodynamic profile in the early post-operative period of heart surgery is carried out.

Figure 1. Lung ultrasound and chest X-ray correlation according to the hemodynamic profile in heart surgery post-operated patients. In $1 \mathrm{~A}$, anteroposterior $X$-ray with portable equipment is shown, without evident radiographic alterations, which is indicative of a patient without lung compromise. In 1B, lung ultrasound reveals the

\section{Correspondence:}

*Luis E. Santos-Martínez

E-mail: luis.santos@cardiologia.org.mx

2604-7063 / @ 2019 Instituto Nacional de Cardiología Ignacio Chávez. Published by Permanyer. This is an open access article under the CC BY-NC-ND license (http://creativecommons.org/licenses/by-nc-nd/4.0/).

Available online: 04-09-2020 Arch Cardiol Mex (Eng). 2020;90(2):225-228 www.archivoscardiologia.com
Date of reception: 31-07-2019

Date of acceptance: 12-12-2019 


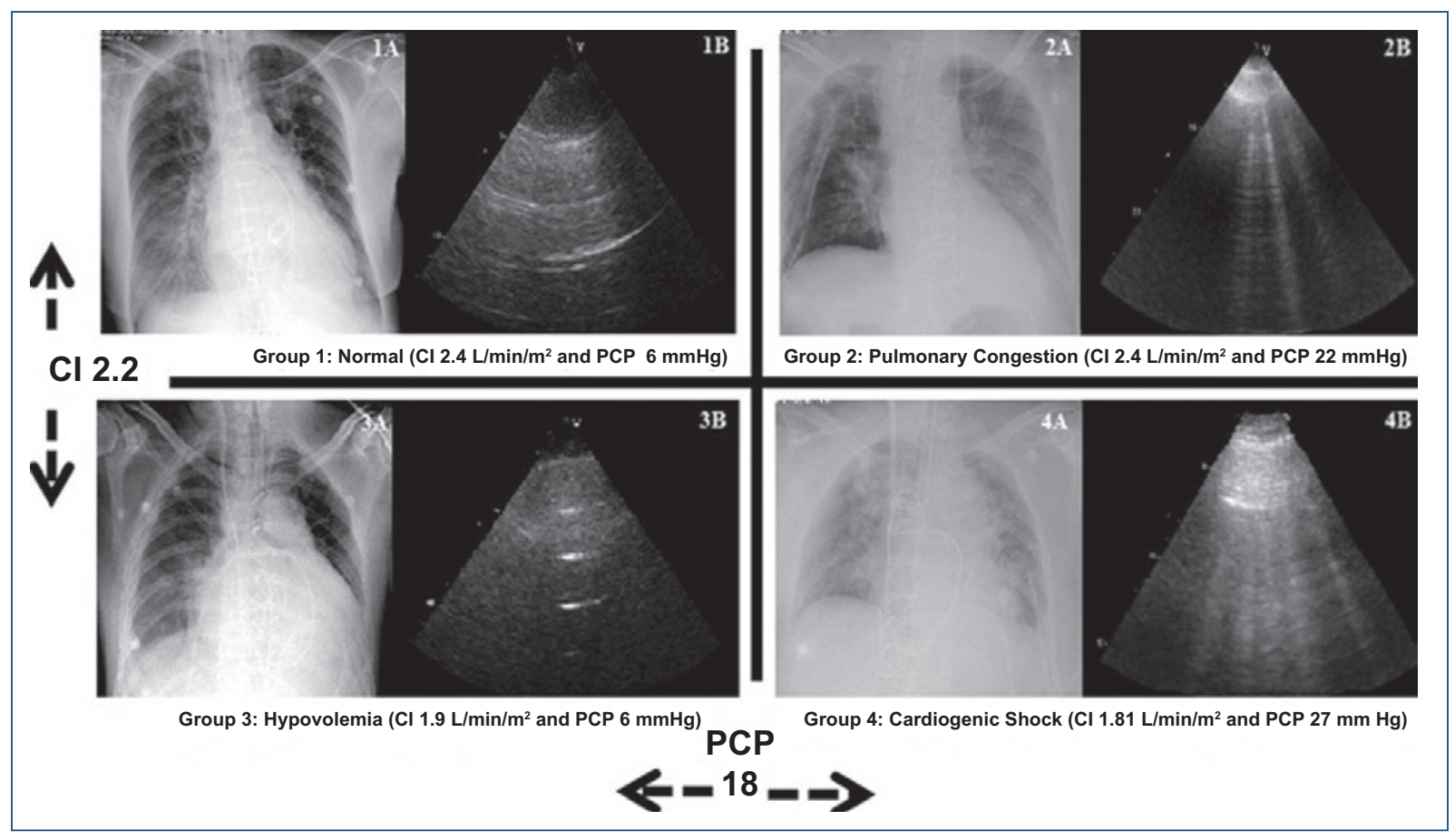

Figure 1. Lung ultrasound and chest $X$-ray correlation according to the hemodynamic profile in heart surgery postoperated patients. In 1A, anteroposterior X-ray with portable equipment is shown, without evident radiographic alterations, which is indicative of a patient without lung compromise. In $1 \mathrm{~B}$, lung ultrasound reveals the bat sign, the pleural line, and A-lines indicative of normal lung; hemodynamic pattern without alterations by cardiac index (CI) and normalized left ventricle filling pressures (pulmonary capillary pressure, $P C P$ ). In $2 A$, anteroposterior $X$-ray shows an increase in bronchovascular bilateral weave, flow cephalization, left costodiaphragmatic effacement, with hemodynamic pattern, increased PCP and pulmonary congestion. In 2B, lung ultrasound identifies the bat sign, the pleural line, and $B$-lines suggestive of alveolar-interstitial syndrome due to pulmonary congestion, in addition to a hemodynamic pattern with normal $\mathrm{Cl}$ and increased PCP and acute pulmonary edema. In $3 \mathrm{~A}$, anteroposterior $\mathrm{X}$-ray shows no apparent lung involvement. In $3 \mathrm{~B}$, anteroposterior lung ultrasound reveals the presence of bat sign, pleural line, and $\mathrm{A}$-lines consistent with normal or dry lung, in addition to hemodynamic pattern with normal $\mathrm{Cl}$ and low PCP due to hypovolemic shock. In 4A, anteroposterior X-ray indicates bilateral bronchovascular weave increase, interstitial occupation and effacement of both costodiaphragmatic angles. In $4 \mathrm{~B}$, pulmonary ultrasound recognizes the bat sign, the pleural line and $\mathrm{B}$-lines indicative of alveolar-interstitial syndrome due to pulmonary congestion, together with hemodynamic pattern with low cardiac index and filling pressures (PCP) elevation due to cardiogenic shock.

bat sign, the pleural line, and A-lines indicative of normal lung; hemodynamic pattern without alterations by cardiac index $(\mathrm{Cl})$ and normalized left ventricle filling pressures (pulmonary capillary pressure, PCP). In 2A, anteroposterior $\mathrm{X}$-ray shows an increase in bronchovascular bilateral weave, flow cephalization, left costodiaphragmatic effacement, with a hemodynamic pattern, increased PCP, and pulmonary congestion. In 2B, lung ultrasound identifies the bat sign, the pleural line, and B-lines suggestive of alveolar-interstitial syndrome due to pulmonary congestion, in addition to a hemodynamic pattern with normal $\mathrm{Cl}$ and increased PCP and acute pulmonary edema. In $3 \mathrm{~A}$, anteroposterior X-ray shows no apparent lung involvement. In $3 \mathrm{~B}$, anteroposterior lung ultrasound reveals the presence of bat sign, pleural line, and A-lines consistent with normal or dry lung, in addition to hemodynamic pattern with normal $\mathrm{Cl}$ and low PCP due to hypovolemic shock. In 4A, anteroposterior X-ray indicates bilateral bronchovascular weave increase, interstitial occupation, and effacement of both costodiaphragmatic angles. In 4B, pulmonary ultrasound recognizes the bat sign, the pleural line, and B-lines indicative of alveolar-interstitial syndrome due to pulmonary congestion, together with hemodynamic patterns with low cardiac index and filling pressures (PCP) elevation due to cardiogenic shock.

Herein, the behavior of the different hemodynamic profiles according to Forrester-Diamond-Swan classification (which correlates the magnitude of cardiac index and pulmonary capillary pressure with four possible profiles) in 
cardiac surgery post-operated patients is described; figure 1 shows the correlation of L-US and chest X-ray obtained with a portable device for these same categories:

- Class 1: Normal profile (cardiac index [Cl] $>2.2 \mathrm{~L} / \mathrm{min} / \mathrm{m}^{2}$; pulmonary capillary pressure $[\mathrm{PCP}]$ $<18 \mathrm{mmHg}$ ). Seventy-one-year-old female patient, post-operated of mitral valve exchange with biological prosthesis plus tricuspid valve plasty; hemodynamic profile at PCICU admission: $\mathrm{Cl}$ of $2.4 \mathrm{~L} / \mathrm{min} / \mathrm{m}^{2}$; and PCP of $14 \mathrm{mmHg}$, stable evolution and extubation at $48 \mathrm{~h}$ (Fig. $1 \mathrm{~A}$ and $\mathrm{B}$ ).

- Class 2: Profile consistent with pulmonary congestion $\left(\mathrm{Cl}>2.2 \mathrm{~L} / \mathrm{min} / \mathrm{m}^{2} ; \mathrm{PCP}>18 \mathrm{mmHg}\right.$ ). Eighty-fouryear-old male patient, post-operated of aortic valve replacement by biological prosthesis plus mitral plasty with a rigid ring; complicated with vasoplegic syndrome requiring intensive fluid resuscitation and use of high-dose vasopressors (at the moment of the images, water balance was positive: $9,600 \mathrm{~cm}^{3}$ ); hemodynamic profile at $\mathrm{PCICU}$ admission: IC of $2.4 \mathrm{~L} / \mathrm{min} / \mathrm{m}^{2}$ and PCP of $22 \mathrm{mmHg}$; left ventricle (LV) ejection fraction was normal (Fig. $2 \mathrm{~A}$ and $\mathrm{B}$ ).

- Class 3: Profile consistent with hypovolemia $\left(\mathrm{Cl}<2.2 \mathrm{~L} / \mathrm{min} / \mathrm{m}^{2}\right.$ and PCP $\left.<18 \mathrm{mmHg}\right)$. Forty-sixyear-old male patient, post-operated of mitral valve plasty with a rigid ring who had more than usual bleeding (1000 $\mathrm{cm}^{3}$ in $2 \mathrm{~h}$ ). Hemodynamic profile at PCICU admission: $\mathrm{Cl}$ of $1.9 \mathrm{~L} / \mathrm{min} / \mathrm{m}^{2}$ and $9-\mathrm{mmHg}$ PCP; LV ejection fraction of $45 \%$ (Fig. $3 \mathrm{~A}$ and $\mathrm{B}$ ).

- Class 4: Profile consistent with cardiogenic shock $(\mathrm{Cl}<2.2 \mathrm{~L} / \mathrm{min} / 2$ and PCP $>18 \mathrm{mmHg})$. Sixty-fiveyear-old female patient, post-operated of a coronary artery bypass graft procedure with left mammary artery to anterior descending artery and left radial artery to first right ventricular branch, who experienced peri-procedural infarction, with new LV hypokinesia on anterior aspect and apex; hemodynamic profile at PCICU admission: $\mathrm{Cl}$ of $1.81 \mathrm{~L} / \mathrm{min} / \mathrm{m}^{2}$ and PCP of $27 \mathrm{mmHg}$; LV ejection fraction of $25 \%$. Double inotropic regimen and intra-aortic balloon pump counterpulsation were required (Fig. $4 \mathrm{~A}$ and $\mathrm{B}$ ).

As it can be observed in the hemodynamic profiles, chest X-ray, and L-US, PCP increase-related pulmonary congestion $n^{1,3,10}$ is a regular event and, actually. it reflects the conditions LV end-diastolic pressure is even in cardiac procedure post-operated patients.

A $3^{\text {rd }}$ day of heart surgery, L-US has been shown to detect complications such as pulmonary congestion ( $p=0.043)$, atelectasis $(p<0.001)$, pneumothorax, pleural effusion $(p=0.013)$, and consolidation ${ }^{11}$ earlier and in larger quantities.
Furthermore, in other clinical scenarios, the presence of EVLW (pulmonary edema, pulmonary congestion) has been linked to decompensation and mortality in acute heart failure ${ }^{8}$.

It should be pointed out that, despite these and other evidences, when PCP has been tried to be correlated with L-US-defined EVLW, it has been low $^{4}$ in the studied population.

It should be noted that L-US does not differentiate by itself between cardiogenic and of non-cardiogenic origin acute edema (EVLW, pulmonary congestion) ${ }^{12}$, and for this reason, both have received the name of the alveolar-interstitial syndrome, with its sonographic translation being $\mathrm{B}$-lines.

B-lines are formed due to different acoustic impedance produced by the pulmonary water-air interface and cause reverberation that on the screen can be seen in the form of vertical lines referred to as comet tail pattern. As the balance between interstitial water increases and alveolar air decreases, the interlobular septum thickens. The alveoli are filled with fluid and this results in the appearance of multiple diffuse B-lines ${ }^{5-7}$. With L-US, sensitivity and specificity have been reported to be $93.4 \%$ and $93 \%{ }^{9}$, respectively.

It is important mentioning that EVLW (pulmonary edema or pulmonary congestion), of cardiogenic or hydrostatic origin, is associated with an imbalance of the Starling mechanisms that favor the increase of water in the interstitial space. Those in charge of moving excess EVLW are the lymphatics, which are identified on chest X-ray as Kerley B-lines when they are engorged. When this mechanism is insufficient, alveolar fluid appears ${ }^{7,8,10,12}$.

Cardiac surgery POP patient is subjected to cardiogenic and non-cardiogenic mechanisms that are complicated by EVLW ${ }^{2}$; in this context, the sequence of episodes can be different for the presence of EVLW, which might explain the possible lack of correlation between PCP and EVPW in other studies ${ }^{4}$.

In the absence of other cardiopulmonary complications and PCP elevation, at least at stages 1 and 3 , the lung is free of EVLW; not so for Forrester-DiamondSwan stages 2 and 4, where it is shown by chest L-US and X-ray with portable equipment; the obtained images are highly indicative of EVLW.

\section{Funding}

The present work did not receive internal or external to the Institution financing. 


\section{Conflicts of interest}

The authors declare that there are no conflicts of interest related to this work.

\section{Ethical disclosures}

Protection of people and animals. The authors declare that no experiments on humans or animals were performed for this investigation.

Confidentiality of data. The authors declare that they have followed the protocols of their work center on the publication of patient data.

Right to privacy and informed consent. The authors have obtained informed consent from the patients and/or subjects referred to in the article.

\section{References}

1. Engelman DT, Ben-Ali W, Williams JB. Guidelines for perioperative care in cardiac surgery. Enhanced recovery after surgery society recommendations. JAMA Surg. 2019; doi:10.100/jamasurg.2019.1153.
2. Santos-Martínez LE, Garduño-López J, Mendoza-Copa G. El ultrasonido pulmonar en la evaluación del síndrome alveolo-intersticial en el postoperatorio de cirugía valvular aórtica e hipertensión pulmonar. Arch Cardiol Mex. 2019;89(3):1-4.

3. van Diepen S, Katz JN, Albert NM. Contemporary management of cardiogenic shock. A scientific statement from the American Heart Association. Circulation 2017;136:e232-e68.

4. Cantinotti M, Giordano R, Volpicelli G. Lung ultrasound in adult and paediatric cardiac surgery: is it time for routine use? Interact CardioVasc Thorac Surg. 2016;22:208-15.

5. Picano E, Chiara-Scali M, Ciampi Q. Lung ultrasound for the cardiologist. J Am Coll Cardiol Img. 2018;11:1692-705.

6. Volpicelli G, Melniker LA, Cardinale L. Lung ultrasound in diagnosing and monitoring pulmonary interstitial fluid. Radiol Med. 2013;118(2);196-205.

7. Cortellaro F, Ceriani E, Spinelli M. Lung ultrasound for monitoring cardiogenic pulmonary edema. Intern Emerg Med. 2016; doi 10.1007/ s11739-016-1510-y.

8. Miglioranza $\mathrm{MH}$, Picano E, Badano LP. Pulmonary congestion evaluated by lung ultrasound predicts decompensation in heart failure outpatients. Int J Cardiol. 2017;240:271-78.

9. Frassi F, Gargani L, Tesorio P. Prognostic value of extravascular lung water assessed with ultrasound lung comets by chest sonography in patients with dyspnea and/or chest pain. J Cardiac Fail. 2007;13:830-5.

10. Arias-Mendoza MA, Rojas-Velasco G, Vieyra-Herrera G. Insuficiencia cardíaca aguda e insuficiencia cardíaca descompensada. Arch Cardiol Mex. 2007;77 (S1):27-33

11. Touw HR, Parlevliet KL, Beerepoot M. Lung ultrasound compared with chest X-ray in diagnosing postoperative pulmonary complications following cardiothoracic surgery: a prospective observational study. Anaesthesia 2018;73:946-954.

12. Spadaro S, Park M, Turrini C. Biomarkers for acute distress respiratory syndrome and prospects for personalized medicine. J Inflammation 2019;16:1-11. 